\title{
Chemistry and Processing of Nanostructured Materials
}

\author{
G. A. Fox, T. F. Baumann, L. J. Hope-Weeks, A. L. Vance
}

January 18, 2002

U.S. Department of Energy

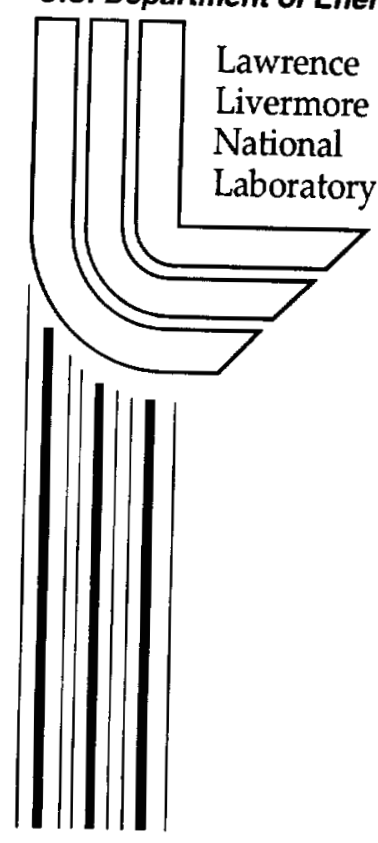




\section{DISCLAIMER}

This document was prepared as an account of work sponsored by an agency of the United States Government. Neither the United States Government nor the University of California nor any of their employees, makes any warranty, express or implied, or assumes any legal liability or responsibility for the accuracy, completeness, or usefulness of any information, apparatus, product, or process disclosed, or represents that its use would not infringe privately owned rights. Reference herein to any specific commercial product, process, or service by trade name, trademark, manufacturer, or otherwise, does not necessarily constitute or imply its endorsement, recommendation, or favoring by the United States Government or the University of California. The views and opinions of authors expressed herein do not necessarily state or reflect those of the United States Government or the University of California, and shall not be used for advertising or product endorsement purposes.

This work was performed under the auspices of the U. S. Department of Energy by the University of California, Lawrence Livermore National Laboratory under Contract No. W-7405-Eng-48.

This report has been reproduced directly from the best available copy.

Available electronically at http://www.doc.gov/bridge

Available for a processing fee to U.S. Department of Energy

And its contractors in paper from

U.S. Department of Energy

Office of Scientific and Technical Information

P.O. Box 62

Oak Ridge, TN 37831-0062

Telephone: (865) 576-8401

Facsimile: (865) 576-5728

E-mail: reports@adonis.osti.gov

Available for the sale to the public from

U.S. Department of Commerce

National Technical Information Service 5285 Port Royal Road

Springfield, VA 22161

Telephone: (800) 553-6847

Facsimile: (703) 605-6900

E-mail: orders@ntis.fedworld.gov

Online ordering: http://www.ntis.gov/ordering.htm

\section{OR}

Lawrence Livermore National Laboratory

Technical Information Department's Digital Library

http://www.llnl.gov/tid/Library.html 


\section{Chemistry and Processing of Nanostructured Materials}

Principal Investigator: Glenn A. Fox

Co-Investigators: Theodore F. Baumann, Louisa J. Hope-Weeks, Andrew L. Vance

Chemistry and Material Science Directorate

Lawrence Livermore National Laboratory

Tracking Number: 99-ERD-004

\section{Introduction}

Nanostructured materials can be formed through the sol-gel polymerization of inorganic or organic monomer systems. For example, a two step polymerization of tetramethoxysilane (TMOS) was developed such that silica aerogels with densities as low as $3 \mathrm{~kg} / \mathrm{m}^{3}$ ( two times the density of air) could be achieved. ${ }^{1,2}$ Organic aerogels based upon resorcinol-formaldehyde and melamine-formaldehyde can also be prepared using the sol-gel process. ${ }^{3-7}$ Materials of this type have received significant attention at LLNL due to their ultrafine cell sizes, continuous porosity, high surface area and low mass density. ${ }^{8}$ For both types of aerogels, sol-gel polymerization depends upon the transformation of these monomers into nanometer-sized clusters followed by crosslinking into a 3-dimensional gel network. While sol-gel chemistry provides the opportunity to synthesize new material compositions, it suffers from the inability to separate the process of cluster formation from gelation. This limitation results in structural deficiencies in the gel that impact the physical properties of the aerogel, xerogel or nanocomposite. In order to control the properties of the resultant gel, one should be able to regulate the formation of the clusters and their subsequent cross-linking.

Towards this goal, we are utilizing dendrimer chemistry to separate the cluster formation from the gelation so that new nanostructured materials can be produced. Dendrimers are three-dimensional, highly branched macromolecules that are prepared in 
such a way that their size, shape and surface functionality are readily controlled. ${ }^{9}$ The dendrimers will be used as pre-formed clusters of known size that can be cross-linked to form an ordered gel network (Figure 1). Consequently, incorporation of dendrimers into the sol-gel process should allow for greater control over both the composition and

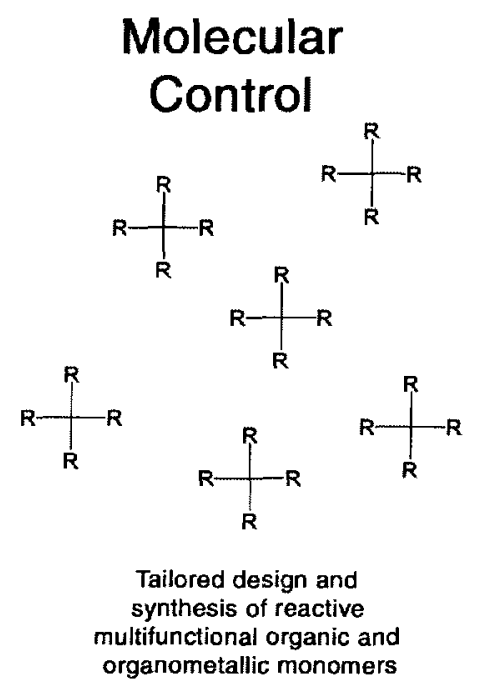

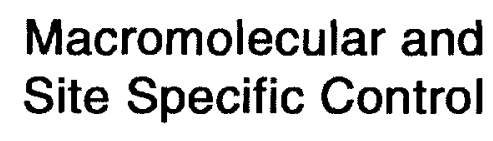

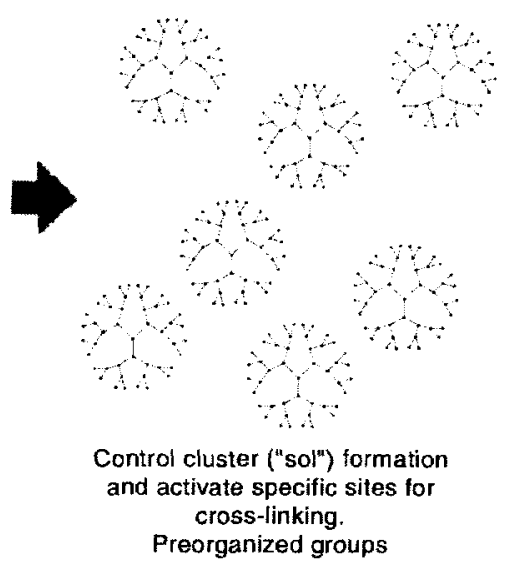

Architechtural Control

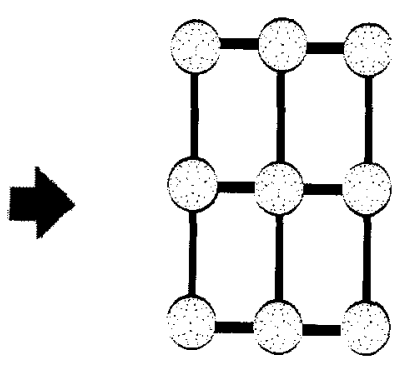

By judicious choice of crosslinking agents, gel formation and properties can be controlled

Figure 1. Incorporation of dendrimers into the sol-gel process

architecture of the resultant nanostructured materials. This approach should address many of the shortcomings currently associated with organic sol-gel chemistry. For example, in many low density organic gels, only $10-15 \%$ of the material is actually interconnected in such a manner that it can support a load, implying that $85-90 \%$ of the mass is present as "dead ends" or "loops."10 Through judicious choice of starting materials and cross-linking agents, we may be able to eliminate these loose ends and improve the structural integrity of the resultant gel. Structural improvements may also effect the processing of sol-gel products, eliminating the lengthy and expensive extraction process. In addition, functionalization of organic aerogels has been, to date, problematic 
and largely unsuccessful. Since the step-wise synthesis of the dendrimers allows us to incorporate specific moieties into their framework, this approach would be an effective way to change the bulk properties of aerogel materials for specific applications. Such functional groups can include organometallic species (catalysis), organic dyes and related moieties (smart materials, sensors) and molecular templates or imprints (membranes, separations, smart materials). This report highlights many of the technical achievements we made in the design of these novel nanostructured materials over the three years (FY99-FY01) of this project.

\section{Technical Accomplishments}

As described earlier, the sol-gel process involves the condensation of monomers into clusters that then cross-link to form the three-dimensional gel network. Our strategy was to use dendrimers as pre-formed clusters with the goal of controlling both the composition and architecture of the resultant aerogel. If we appropriately tailor the surface chemistry of the dendrimers with groups that are reactive under sol-gel conditions, we should be able to control the assembly of the dendrimers into the threedimensional gel network. In addition, the step-wise synthesis of the dendrimers allows for the incorporation of specific functionality into the gel framework. Since the main building blocks for organic aerogels are either resorcinol (1,3-dihydroxybenzene) or melamine (1,3,5-triaminotriazine), our target molecules were dendrimers containing multiple resorcinol or amine units at their periphery. These macromolecules could then be reacted with selected cross-linking agents, such as formaldehyde, under sol-gel conditions to afford new organic aerogels. 
As a first step in the assembly of multi-dendrimer arrays, we prepared a new class of sol-gel materials, termed dendrigels, ${ }^{11}$ based on polyamidoamine (PAMAM) dendrimers. We chose to start with PAMAM dendrimers for three reasons: (1) a range of generations (sizes) is commercially available, (2) the structures of these dendrimers have been studied and (3) we can exploit the synthetic versatility of the amino groups to cross-link the dendrimers. Reaction of the peripheral amino groups of the PAMAM dendrimer with appropriate equivalents of formaldehyde, under conditions analogous to those used to prepare melamine-

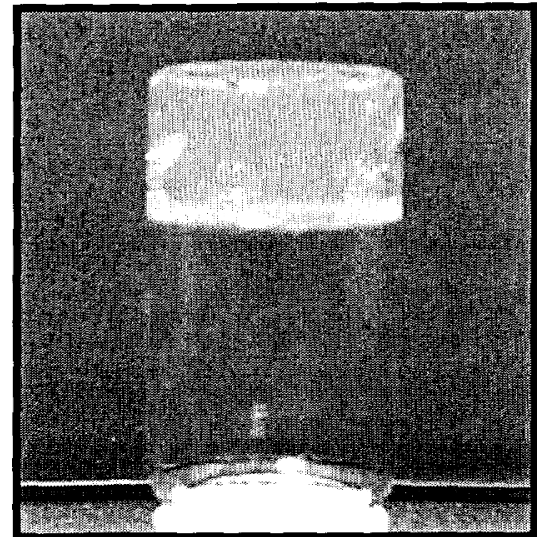

Figure 2. Photograph of the transparent dendrigel in a vial formaldehyde gels, produces highly cross-linked multi-dendrimer networks (Figure 2). Specifically, treatment of PAMAM G3 dendrimer (32 terminal amino groups) in 1:1 (v:v) solution of water and $\mathrm{MeOH}$ with 16 equivalents of formaldehyde $\left(37 \%\right.$ solution in $\left.\mathrm{H}_{2} \mathrm{O}\right)$ affords a stable organic gel. Interestingly, no catalyst was required to initiate the polymerization reaction. In an attempt to obtain an aerogel, the solvent retained in the porosity of the gel was exchanged for acetone prior to supercritical extraction with carbon dioxide $\left(1200\right.$ psi at $\left.50{ }^{\circ} \mathrm{C}\right)$. The structural integrity of the gels is maintained during the solvent exchange, but a significant amount of densification was apparent following the supercritical extraction. The final density of the xerogel monolith was determined to be $\sim 900 \mathrm{mg} / \mathrm{cm}^{3}$. Due to the significant densification that occurred during processing, it was difficult to obtain BET surface area and pore volumes for the xerogel product. We are currently looking to incorporate other cross-linking agents into molecular architecture of the gel. The size and rigidity of these cross-linking agents will 
affect the interconnectivity of the dendrimers and, as a result, judicious choice of crosslinking agents may improve the structural integrity of the materials.

We have also focused our efforts on the preparation of new dendrimers containing multiple resorcinol units at the periphery. Molecules of this type can be synthesized through the incorporation of resorcinol derivatives into the dendrimer framework. A number of important issues, however, had to be addressed prior to the synthesis of these dendrimers. For example, we had to determine if the resorcinol derivatives would retain the reactivity of the parent resorcinol molecule in the sol-gel polymerization process. Another challenge in the synthesis of these materials is finding a suitable protecting group for the hydroxy groups of the resorcinol units. The protecting group must be robust enough to survive the synthesis of the dendrimer, but should be readily cleaved in high yield from the resorcinol groups once the synthesis is complete. In addition, we also needed to find alternative solvent media for the sol-gel reaction since many of these dendrimers will not be soluble in water. We were able to resolve these issues through the use of lower generation (size) dendrimers containing only two or three resorcinol units attached to a central core molecule. In effect, these compounds were used as model compounds for the higher generation dendrimers, without the time and expense associated the synthesis of the larger macromolecules. These model compounds not only allowed us to solve the problems listed above and, therefore, optimize the sol-gel reaction conditions for the larger dendrimers, but they also represent a interesting class of starting materials for novel sol-gel products. Using functional core molecules, such as metal complexes, binding sites or fluorophores, these new sol-gel precursors can be used to prepare functionalized organic aerogels. 
Toward this goal, we synthesized new functionalized aerogels from smaller dendrimers containing a site capable of coordinating metal ions. ${ }^{12}$ Such aerogels may have application as advanced catalyst supports or as adsorbent for metal remediation of waste streams. In general, these sol-gel precursors were synthesized through the reaction of a protected resorcinol derivative with a metal chelate. As a specific example, we reacted the sodium salt of 1,2-ethanedithiol with 3,5-dimethoxybenzyl chloride (the resorcinol derivative). Subsequent removal of the methyl protecting groups from the resorcinol moieties with boron tribromide yielded a new sol-gel precursor capable of coordinating a variety of metal ions. These precursors were polymerized under sol-gel conditions to generate aerogels containing metal binding sites (Figure 3).

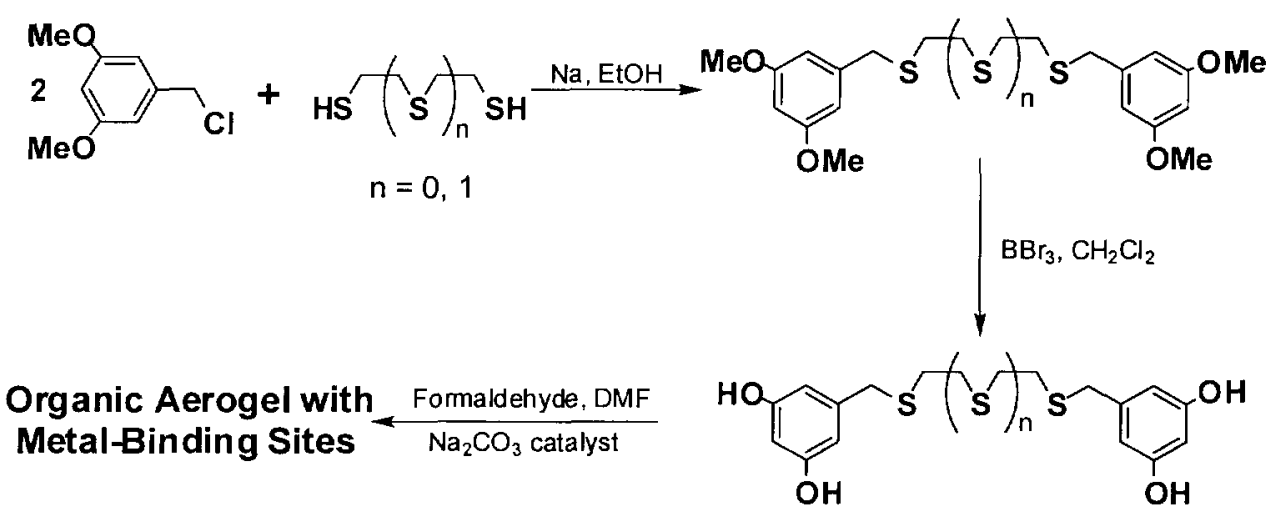

Figure 3. Synthesis of dendrimer model compounds containing multiple resorcinol units

While these functionalized aerogels are inherently interesting in their own right, this work allowed us to optimize the sol-gel process for the higher generation dendrimers. Since these molecules were not soluble in water, we were able to determine alternative solvent systems that were suitable for the non-aqueous sol-gel polymerization of the larger dendrimers. From this work, we were also able to determine which resorcinol derivatives polymerized under sol-gel conditions and which resorcinol protecting groups 
were most compatible with the dendrimer synthesis. All of these results were applied to the synthesis of the higher generation dendrimers.

With a reliable synthetic protocol established, we expanded our efforts to the synthesis of the higher generation dendrimers containing peripheral resorcinol units. We focused on the synthesis of two main types of dendrimers. One class will be used to build function into the aerogel framework. The step-wise synthesis of these dendrimers allows us to incorporate specific moieties (i.e. metal species, binding sites, sensing moieties) into their framework. The other type of dendrimer will be used to improve the structural efficiency of the aerogel network. These dendrimers will be composed of rigid building blocks, reinforcing the extended architecture of the aerogel.

For the synthesis of the functionalized dendrimers, we chose to work with dendrimers in which each generation consists of benzyl ether repeat units. This type of dendrimer ${ }^{13}$ provides a great deal of synthetic flexibility and, as such, we can add specific functional groups to the dendrimer framework, namely with the core molecule. The allyl group was selected as the protecting group since allyl ethers are

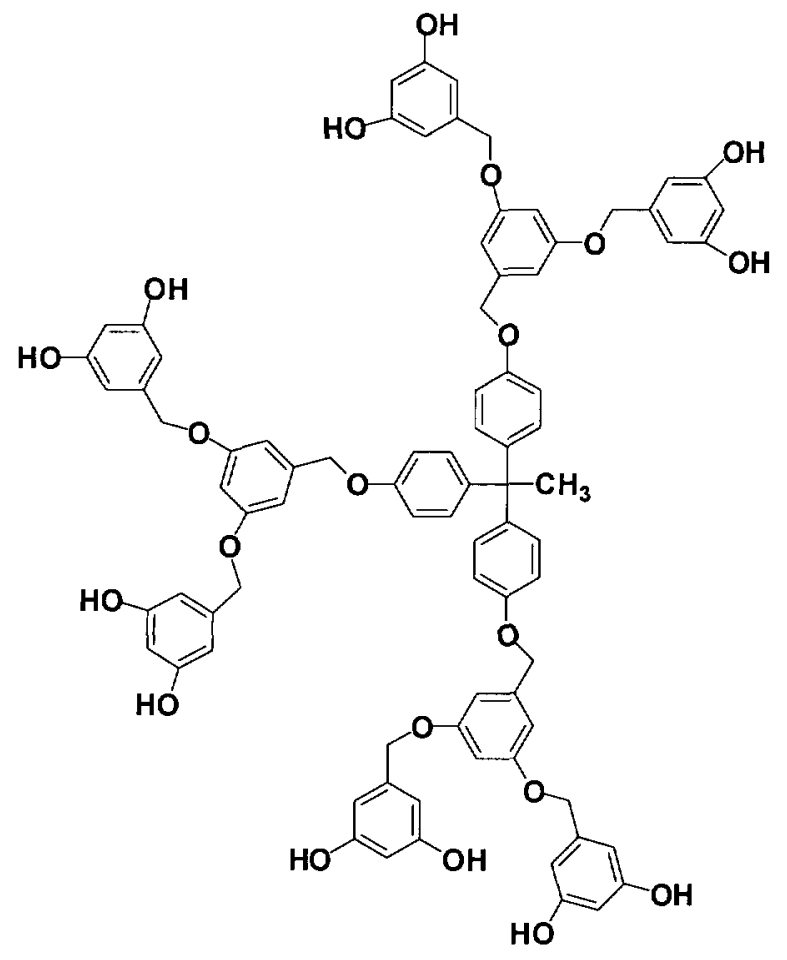

Figure 4. Generation 2 dendrimer containing peripheral resorcinol moieties readily prepared from the resorcinol derivatives and allyl bromide, and cleaved in high yield using bis(triphenylphosphine)palladium dichloride. ${ }^{14}$ Using a convergent growth 
method, we were able to synthesize generation 1 and generation 2 dendrimers containing peripheral resorcinol units (Figure 4). ${ }^{15}$ Once the allyl groups were removed, these dendrimers were then reacted under sol-gel polymerization conditions to generate new organic aerogels. These new aerogels had densities between 200 and $300 \mathrm{mg} \mathrm{cm}^{-3}$ with surface areas similar to those of traditional aerogels. Transmission electron microscopy showed that the primary particle sizes were between 10 to $20 \mathrm{~nm}$ (Figure 5). We are currently focusing on the synthesis of larger generation dendrimers containing some of the

$70.00 \mathrm{~nm}$

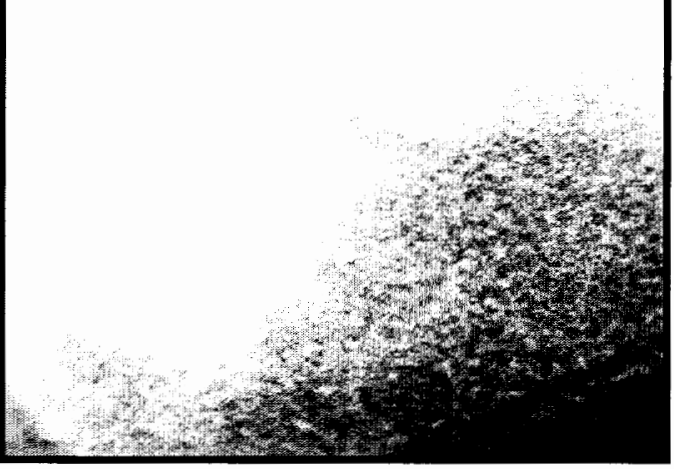

Figure 5. Transmission electron micrograph (TEM) of organic aerogel prepared from dendrimers containing resorcinol units functional groups described above. While the core molecule for these dendrimers was 1,1,1-tris(4-hydroxyphenyl)ethane, the convergent synthesis allows for the incorporation of a variety of functional core molecules into the dendrimer.

For the synthesis of the rigid dendrimers, we chose to employ phenylacetylene units ${ }^{10}$ as our rigid building blocks. These groups should impart greater structural integrity to the aerogel than the repeat units of the functionalized dendrimers. In addition, these dendrimers will be constructed from a rigid core molecule, like adamantane, to further reinforce the structure. For these dendrimers, we selected the methyl protecting group due the easy synthesis of aryl methyl ethers and the robust nature of group. ${ }^{17}$ In addition, we can employ a variety of methods for cleavage of the methyl group (i.e trimethylsillyl iodide or boron tribromide), which provides us with a great deal of flexibility in constructing the dendrimer. With this approach, we were able to prepare a number of 
rigid methyl protected dendrimers (Figure 6). ${ }^{18}$ These materials were prepared through the coupling of the methyl-protected iodoresorcinol derivative with alkyne units using a palladium catalyst. We are currently working on the removal of the methyl groups from the resorcinol units so that these rigid dendrimers can be used to prepare new organic aerogels with improved structural efficiency.

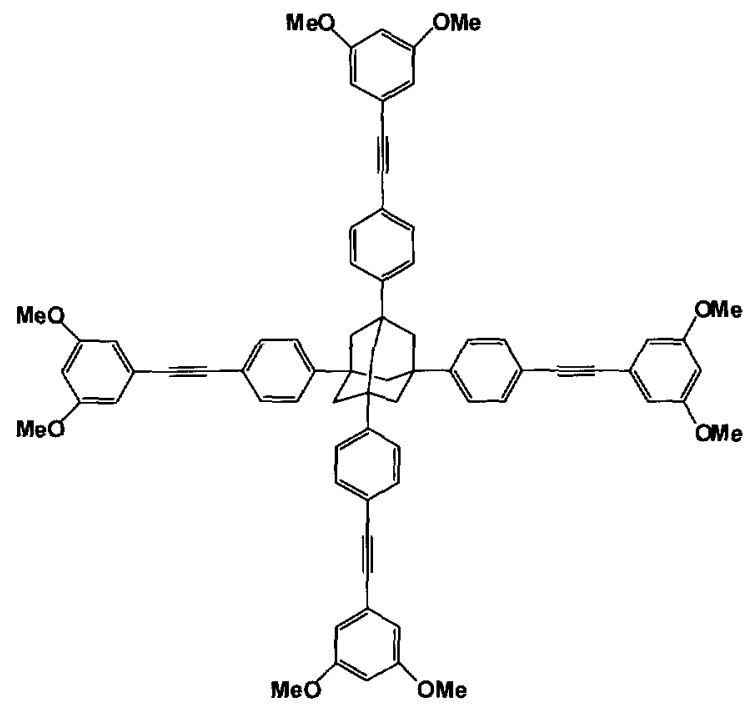

Figure 6. An example of a rigid dendrimer, a methyl-protected dendrimer consisting of an adamantane core and phenylacetylene linkages

\section{Summary}

The overall goal of this project was the incorporation of dendritic methodology into sol-gel synthesis for the design of new tailored nanostructured materials. The synthetic versatility associated with dendrimers should allow us to control both the assembly of the multi-dendrimer arrays as well as the composition and function of the materials. Over the three years of this project (FY99-FY01), we were successful in preparing a number of novel organic aerogels through the sol-gel polymerization of dendrimers. Based on our results, it is clear that the use of dendrimers and related compounds in the sol-gel process can be used to modify both the structure and properties of organic nanostructured materials. This work has been presented at two American Chemical Society National Meetings and has produced one publication, with three more manuscripts in preparation. Most importantly, we have obtained external funding from the DOE Joint DP/BES Nanoscience Network based, in part, on the work presented here. This funding enables 
us to collaborate with groups at Los Alamos, Argonne, Sandia and Pacific Northwest National Laboratories with the goal of designing new tailored nanostructured materials. 


\section{References}

1. Hrubesh, L. W.; Tillotson, T. M.; Poco, J. F. In Chemical Processing of Advanced Materials; Hench, L.L.; West, J.K. Eds.; John Wiley \& Sons, NY, 1992; pp. 19-27.

2. Tillotson, T. M.; Hrubesh, L.W. J. Non-Cryst. Solids 1992, 145, 44.

3. Pekala, R. W. J. Mat. Sci. 1989, 24, 3221.

4. Pekala, R. W.; Alviso, C. T.; Lu, X.; Groß, J.; Fricke, J. J. Non-Crystalline Solids $1995,188,34$.

5. Pekala, R. W.; Schaefer, D. W. Macromolecules 1993, 26, 5487.

6. Pekala, R.W.; Alviso, C. T.; Kong, F. M.; Hulsey, S. S. J. Non-Cryst. Solids 1992, 145,90 .

7. Alviso, C. T.; Pekala, R. W. Polym. Prpts. 1991, 32, 242.9 MRS

8. LeMay, J. D.; Hopper, R. W.; Hrubesh, L. W.; Pekala, R.W. MRS Bulletin 1990, 15, $19-45$.

9. Dendritic Molecules: Concepts, Syntheses, Perspectives; Newkome, G. R.;

Moorefield, C. N.; Vögtle, F, Eds.; VCH Weinheim, 1996.

10. Gross, J.; Scherer, G. W.; Alviso, C. T.; Pekala, R. W. J. Non-Cryst. Solids 1997, $211,132$.

11. Baumann, T. F.; Fox, G. A.; Vance, A. L. ACS Symposium Series, Division of Polymer Chemistry 2001, 15, 33 (UCRL-JC-133875).

12. Baumann, T. F.; Hope-Weeks, L. J.; Fox, G. A. J. Non-Cryst. Solids 2002, manuscript in preparation.

13. Hawker, C. J.; Frechet, J. M. J. J. Am. Chem. Soc. 1990, 112, 7638.

14. Tsuji, J.; Yamakawa, T. Tetrahedron Lett. 1979, 7, 613. 
15. Baumann, T. F.; Hope-Weeks, L. J.; Fox, G. A. Macromolecules 2002, manuscript in preparation.

16. Xu, Z.; Kahr, M.; Walker, K. L.; Wilkins, C. L.; Moore, J. S. J. Am. Chem. Soc., $1994,116,4537$.

17. (a) Jung, M. E.; Lyster, M. A. J. Org. Chem. 1977, 42, 3761. (b) Vickery, E. H.; Pahler, L. F.; Eisenbraun, E. J. J. Org. Chem. 1979, 44, 4444.

18. Hope-Weeks, L. J.; Baumann, T. F.; Fox, G. A. Macromolecules 2002, manuscript in preparation. 